\title{
Astronomers in Europe urge new Hubble pact
}

Paris. European astronomers are putting pressure on the European Space Agency (ESA) to move quickly to extend an agreement with the US National Aeronautics and Space Administration (NASA) guaranteeing them observing time on the Hubble Space Telescope when the existing agreement expires in 2001.

They are worried that, if such action is not taken promptly, they may lose some or all of their access to the telescope in 2001. But ESA is concerned that committing new funds to Hubble in the near future could mean reducing support for other space science projects.

Under the current agreement, European astronomers are guaranteed a minimum of 15 per cent of observing time on the telescope, which was launched in 1990. (In practice, they win around one-fifth, based on competition for scientific proposals.) In return for viewing time, ESA has supplied two sets of solar panels and the Faint Object Camera (FOC). It has also provided 15 members of staff at the Space Telescope Science Institute in Baltimore. ESA officials admit that "[w]e get a very good deal".

But Europe's astronomers say that this honeymoon could end abruptly in 2001 if ESA does not renew its dowry in good time. Indeed, NASA officials say that, if ESA delays commitment too long, it may be "too late"; they also say that financial pressure on the US agency may force it to change its policy of giving other countries such as Australia - the third most frequent user of Hubble - free access to the telescope.

ESA officials say that the astronomers' warning has been registered by the board of the agency, which formally discussed the

\section{ESA plans 'go it alone' collaboration strategy}

Paris. The European Space Agency (ESA), upset at the way in which foreign partners have vacillated over its participation in collaborative projects, has decided that all future missions will be designed so that foreign participation is not essential to achieving their main scientific goals.

Last year, ESA decided to go ahead with a scaled-back version of the first mission (Rosetta) to land instruments on the surface of a comet, without the planned involvement of NASA. This decision was taken after the US agency had indicated that funding for its participation would probably not materialize (see Nature 365, 681; 1993).

ESA has now formally decided to design all missions so that they can be launched and achieve their main scientific goals even if partners pull out.

D. B. issue with NASA for the first time at a meeting last month. Giacomo Cavallo, the head of ESA's science programme coordination and planning office, is keen to reassure astronomers. He says that "ESA is committed to Hubble", and is actively looking at ways to ensure continued participation beyond 2001 .

But many astronomers remain disappointed at the likelihood that towards the end of the decade the agency will limit itself to contributing to the operational costs of the telescope, rather than taking up a proposal to develop jointly with NASA the Advanced Camera, due to be fitted during a servicing mission in 1999 (see Nature 368, 573; 1994).

By that date, the FOC will have been in orbit for nine years, and the Wide Field and Planetary Camera for five, well beyond their design lifetime. ESA officials say the Advanced Camera "would let us go two magnitudes fainter than the $\mathrm{FOC}$, with a field of view four times bigger".

Joining up with NASA would make it possible to double the proposed budget for the camera to around US\$100 million, and provide a 'superior' instrument to that now planned.

According to NASA scientists, however, ESA representatives at last month's meeting "made it very clear that they were not interested" in helping to develop the camera. Cavallo says the main obstacle is that ESA would have to find US\$50 million immediately, as the camera would have to be built within three years, and that this would mean delaying other projects.

But Cavallo adds that even if ESA cannot take part in building the Advanced Camera, European astronomers will still be free to participate directly. He says that ESA will encourage NASA to seek help from Europe's national space agencies, and might be in a position to make a small additional contribution to such efforts. Declan Butler

\section{Spain likely to beg poverty at CERN}

Munich. Spain is threatening to cast a shadow over next month's expected approval of the Large Hadron Collider (LHC) at the European Laboratory for Particle Physics (CERN) by continuing to demand a significant reduction in its annual contributions to the organization.

Spain has withheld its subscription to CERN for the past two years on the grounds that it wants a better return on its investment, and it now owes the laboratory SFr 130 million (US\$90 million). Earlier this month, it asked for more time to consider a compromise offer of a 20 per cent discount in its subscription over the next five years, having originally asked for a 30 per cent reduction.

But Spain's actions have annoyed some of CERN's major member states, which argue that it has reaped significant political advantages from its decision to join CERN in the $1980 \mathrm{~s}$ - a prelude to becoming a full member of the then European Economic Community - and that the amount of money in dispute is relatively small compared with the economic benefits it has obtained.

Contributions from CERN's 19 member states are based on gross national product (GNP), averaged over the previous three years. Spain's economic spurt during the 1980 s meant that its subscription grew by nearly 50 per cent between 1989 and 1993 . It now pays around 8 per cent of CERN's total budget, making it the fifth biggest contributor.

But Spain's economic boom was short lived, and the country is now deep in recession. Furthermore, Spanish officials complain that, when measured against financial contributions, Spain has the lowest number of staff and visiting scientists at CERN, and wins less than 1 per cent of the total value of industrial contracts issued each year.

The dispute seemed near resolution earlier this month when CERN council members were asked to consider a proposal from Christopher Llewellyn-Smith, the laboratory's director-general, and Hubert Curien, the president of its council, following negotiations with Spanish delegates and government officials in Madrid.

Under this proposal, Spain would repay its outstanding debt immediately by underwriting a loan taken out by CERN, and in return would get a discount on its contributions over the next five years. Reductions would be on a sliding scale, starting with 40 per cent this year when economic problems are particularly hard, and averaging 20 per cent reduction over five years.

Elias Fereres, the secretary of state for universities and research, says that the two sides are close, and hopes for a quick resolution. But Fereres has limited influence over the decision. Although his ministry is responsible for Spain's scientific activities in CERN, for historical reasons the budget is controlled by the ministry of industry, which has little interest in fundamental science, while the ministry of finance, which ultimately holds the purse-strings, is taking a very tough line.

Llewellyn-Smith wants the issue resolved before CERN's council meeting in June, when member states will vote - it is hoped unanimously - on the approval of LHC.

Alison Abbott 